A N N A L E S Annales de Bretagne et des Pays de l'Ouest

Anjou. Maine. Poitou-Charente. Touraine

$120-4 \mid 2013$

Varia

\title{
Bernard Merdrignac et les ABPO
}

Annie Antoine et Daniel Pichot

\section{OpenEdition}

Journals

Édition électronique

URL : http://journals.openedition.org/abpo/2666

DOI : $10.4000 /$ abpo. 2666

ISBN : 978-2-7535-3304-2

ISSN : 2108-6443

Éditeur

Presses universitaires de Rennes

Édition imprimée

Date de publication : 30 décembre 2013

Pagination : 9

ISBN : 978-2-7535-3302-8

ISSN : 0399-0826

Référence électronique

Annie Antoine et Daniel Pichot, «Bernard Merdrignac et les ABPO », Annales de Bretagne et des Pays de l'Ouest [En ligne], 120-4 | 2013, mis en ligne le 30 décembre 2013, consulté le 23 septembre 2020. URL : http://journals.openedition.org/abpo/2666 ; DOI : https://doi.org/10.4000/abpo.2666 


\section{Bernard Merdrignac et les ABPO}

Bernard a pris le poste de secrétaire des Annales de Bretagne et des Pays de l'Ouest quasiment dès son arrivée à l'université, en 1992 puis, en 1998, succédant à J. Quéniart, il devint président de l'Association pour la publication des $A B P O$, ceci jusqu'en 2010, date de son départ en retraite. Pendant 18 ans, il a donc occupé des places stratégiques et a marqué profondément la revue.

Soucieux d'efficacité et d'ouverture, il s'attacha à faire du comité de rédaction un vrai comité de lecture, lieu de discussion et de décision. Les équilibres entre les diverses universités associées furent toujours soigneusement préservés, ce que démontre parfaitement la répartition des articles et des numéros spéciaux de la revue. Bernard joua aussi un rôle important dans la mise en place d'un conseil scientifique international afin de mieux assurer la qualité des articles et d'ouvrir davantage sur la recherche étrangère. Il eut à cœur de publier des articles provenant particulièrement de l'Arc atlantique et surtout, il sollicita des collègues britanniques et irlandais sur les sujets qui coïncidaient avec ses propres recherches sur les mondes celtiques. Grâce à cette politique, les Annales purent faire connaître ce qui se passait outre-Manche.

De la même manière, il chercha à améliorer le contenu de la revue, sachant solliciter et attirer. Sous son mandat furent publiés des textes concernant toutes les époques, rendant compte de la diversité des courants qui s'exprimaient dans la recherche, ce qui n'était pas aisé en raison du foisonnement des approches et des sujets depuis les années 90 . Les $A B P O$ diffusèrent les travaux de chercheurs confirmés aussi bien que les essais de débutants, mémoires de DEA puis de master, offrant ainsi leurs premières publications à de jeunes chercheurs. Elles furent le lieu de publication tant de grands articles de synthèse que de recherches très pointues et érudites.

Bernard souhaita que les $A B P O$ se placent au cœur de la recherche dans le Grand Ouest Aussi voulut-il faire toute sa place à l'archéologie, refusant de la réduire au rang subalterne de science auxiliaire. Dans le même esprit, il renoua avec l'ancienne tradition de publier, chaque année, une chronique des archives tout comme, dès 2003, il lançait le bilan annuel des recherches dans les universités : DEA, masters et thèses soutenus. Pendant longtemps il géra les comptes-rendus et il mit largement la main à la pâte. Infatigable lecteur, il en rédigea en nombre, sur l'hagiographie bien sûr, mais sa large curiosité lui fit dépasser ce domaine.

Grâce à ses qualités humaines, il avait su développer un esprit d'équipe et les $A B P O$ lui doivent beaucoup. Pour tout cela, il laisse un profond souvenir d'amitié, mais il a surtout contribué à forger une revue qu'il voulait de référence.

Annie AntoINe, Daniel PICHOT 